\title{
The Mediating Role of Social Phobia Between Perfectionism and Low Life Satisfaction Among Young Women
}

\author{
Bianka Dobos ${ }^{1}$, Robert Urban², Dianna Kenny ${ }^{3}$, Bettina F. Piko ${ }^{4 *}$
}

\begin{abstract}
Individuals with social phobia report lower quality of life, poorer social functioning and lower achievement. Young women are more likely to experience anxiety than other demographic groups. Using bidirectional associations and a path model, this study examined the interrelationship between social phobia and trait anxiety, perfectionism and self-efficacy, and the role these variables play in the life satisfaction of 394 females aged between 18 and 35 . Correlational analysis revealed that women with higher levels of trait anxiety, social phobia and perfectionism and lower levels of perceived self-efficacy were less satisfied with their life. Greater satisfaction with life was achieved by those who had higher self-efficacy, lower trait anxiety, less perfectionism and fewer social fears. In the final path model, the mediated effect of perfectionism, social phobia and satisfaction with life was significant. Social phobia fully mediated the link between perfectionism and low life satisfaction. These results suggest that perfectionism indirectly affects satisfaction with life through its contribution to the experience of social phobia. Overall, these results support the role of social phobia in young women's lower satisfaction with life. In addition, perfectionism - indirectly, through developing social phobia - may also contribute to lower levels of life satisfaction, while self-efficacy does not mediate these interrelationships.
\end{abstract}

\section{Keywords}

anxiety disorder, social phobia, perfectionism, satisfaction with life, self-efficacy, trait anxiety

1 University of Szeged, Hungary

${ }^{2}$ Eötvös Loránd University, Budapest, Hungary

${ }^{3}$ University of Sydney, Australia

${ }^{4}$ University of Szeged, Hungary

*Corresponding author: fuzne.piko.bettina@med.u-szeged.hu

\section{Introduction}

Anxiety affects a large percentage of the population, with social phobia and specific phobias being the most common among all anxiety disorders (Bandelow \& Michaelis, 2015). The prevalence rates are about twice as high for women (Auerbach et al., 2018), which is specifically burdening for females aged between 15 and 34 (Baxter, Vos, Scott, Ferrari, \& Whiteford, 2014). Social phobia, defined as the fear of negative evaluation (Bautista \& Hope, 2015), is characterized by an intense fear of social situations, which can lead to avoidance of social encounters and restricted social functioning (Heeren \& McNally, 2018; Tahmassian \& Moghadam, 2011). Individuals with social phobia experience fear of attention even from a small group of people (Jefferson, 2001). By focusing on their internal feelings, they become unable to concentrate on objective reality because of the fear of negative evaluation (Bautista $\&$ Hope, 2015). Dysfunctional cognitive schemas, comprising negative core beliefs (i.e. low self-efficacy) are activated during the appraisal phase of a threatening event (Tahmassian $\&$ Moghadam, 2011). The individual then enacts safety behaviours, such as avoiding or escaping the perceived threat. The result is an anxiety response, which feeds back into the negative core beliefs and assumptions in a vicious cycle. Social phobia can develop as a result of previous negative exposure to a situation over which the individual experienced a lack of control. Individual differences in trait anxiety contribute to the effects of negative exposure (Antony \& Barlow, 2002). This is particularly common in people with depression (de Bles et al., 2019). Studies often link social anxiety with excessive alcohol or illicit drug use (Blumenthal, Taylor, Cloutier, Baxley, \& Lasslett, 2019). The greater the social fears, the more negatively it will affect overall mental health. Individuals with social anxiety also show decreased mean scores for life satisfaction both globally but especially in domains requiring social competence, such as friendships, partnerships and family. As a result, individuals with social anxiety disorder report lower quality of life and poorer social functioning (Dryman, Gardner, Weeks, \& Heimberg, 2016).

Relative to other anxiety disorders, social phobia is asso- 
ciated with greater concerns about mistakes and doubts about actions, in addition to the experience of shame and the need to correct mistakes (Egan, Wade, \& Shafran, 2011). Not surprisingly, there is a close connection between social phobia and maladaptive perfectionism (Nepon, Flett, Hewitt, \& Molnar, 2011), defined as striving for flawless and therefore unattainable performances (Bieling, Israeli, \& Antony, 2004). On the other hand, adaptive perfectionism, defined as an intense effort to achieve a realistic goal, is often associated with greater selfefficacy and higher life satisfaction (Chen et al., 2017). Maladaptive perfectionists equate a perfect "performance" with self-worth and an impaired performance with worthlessness. Consequently, maladaptive perfectionists fail regularly, thus rendering themselves prone to chronic anxiety, depression, low self-esteem and self-efficacy, embarrassment and shame (Nepon et al., 2011).

Self-efficacy may be an important factor in promoting psychological well-being and life satisfaction (Burger \& Samuel, 2017), and reducing the negative effect of anxiety and maladaptive perfectionism. Included in Bandura's (1977) selfefficacy theory, it is the ability to perceive oneself as capable and adequately prepared to accomplish a certain goal. The level of self-efficacy determines whether any coping mechanism will be activated and the degree of effort that will be invested to face the obstacles Bandura (1977). In stressful situations, self-efficacy can be a great resource (Morina et al., 2018). People who do not believe that they can exercise control over potential threats experience high levels of anxiety arousal (Bandura, 1977). While young adults experience many concurrent changes in all aspects of their lives, those who report higher self-efficacy also gain higher levels of life satisfaction (Çakar, 2012). Higher self-efficacy scores in university students predicted both higher satisfaction with life and happiness (van Zyl \& Dhurup, 2018); thus, self-efficacy seems to facilitate both satisfaction with life and happiness in general. The relationship between self-efficacy and perfectionism is not unequivocal: some aspects, for example, self-oriented and other-oriented perfectionism are associated with lower self-efficacy, while higher levels of socially-prescribed perfectionism are associated with higher self-efficacy (Hart, Gilner, Handal, \& Gfeller, 1998).

\section{The Present Study}

The literature suggests that social phobia is a mental disorder that impairs quality of life. Therefore, this study investigated the impact of social phobia on young women's satisfaction with life. Although some of these connections have already been demonstrated, we examined these associations in a complex model. Since some studies also suggest that there is a close connection between social phobia and perfectionism, the role of perfectionism was explored in a path model that included trait anxiety and self-efficacy, to take a closer look at their interaction with social phobia and satisfaction with life. Therefore, the main goals of the current study were: (a) to examine the bi-variate relationships between trait anxiety, social phobia, perfectionism, self-efficacy and satisfaction with life; and (b) to explore the mediating role of these variables in satisfaction with life in a sample of young women. Based on the literature, the hypotheses generated for the present study were the following:

H1: Female students have elevated social phobia levels.

$\mathrm{H} 2$ : Social phobia is related to trait anxiety and perfectionism. H3: Lower satisfaction with life can be observed in those with higher social phobia and perfectionism scores.

H4: Higher mean scores of social phobia and perfectionism are related to lower mean scores on self-efficacy.

\section{Method}

\section{Samples}

Data was collected with a self-reported online questionnaire by means of different social networking sites (e.g. Facebook groups). A total of 394 responses were received from young women aged between 18-35. The mean age was 27.5 $(S D=5.5$ years). This specific age group was selected due to the high impact of social phobia on the quality of life described in previous findings (see Baxter et al., 2014; Merikangas, Avenevoli, Acharyya, Zhang, \& Angst, 2002).

\section{Measures}

The study included five scales:

Symptoms of social phobia were assessed with Social Phobia Inventory (SPIN; Connor et al., 2000). This self-report inventory evaluates the symptoms of nonspecific social phobia on a 5-point Likert scale from ( $1=$ not at all to $5=$ extremely). The 17-item scale includes items such as "Being criticized scares me a lot." In previous studies, the SPIN has demonstrated the capacity to differentiate youth with social phobia (SP) and those with sub-clinical SP symptoms (SSP), from those without SP. Internal consistency of the scale is excellent $(\alpha=.94)$. Scores range from 0 to 68 with a cut-off score of 19 , identified as the clinically significant cut-off point.

The 20-item trait part of the Hungarian version of the State-Trait Anxiety Inventory (STAI; Spielberger, Gorsuch, \& Lushene, 1970) was used to measure general anxiety. Responses were rated on a 4-point Likert-scale ( 1 = not at all, 5 = very much). Higher scores indicate that anxiety is a stable internal characteristic. The reliability value $(\alpha=.93)$ was also excellent with the current sample.

The Hungarian version of the 35-item Frost Multidimensional Perfectionism Scale (FMPS; Frost, Marten, Lahart, \& Rosenblate, 1990) was applied to measure perfectionism. Responses were scored on a 5-point Likert-type scale, ranging from ( 1 = strongly disagree to $5=$ strongly agree $)$. A typical item of the scale is: "People will probably think less of me if I make a mistake." Higher scores indicated higher tendencies of perfectionism. The Organization items were excluded from the FMPS total scores (Frost et al., 1990, p. 454). Cronbach's alpha value of internal consistency for the whole scale was .92.

Self-efficacy was assessed with the Hungarian adapted version of the General Perceived Self-Efficacy Scale (Schwarzer 
\& Jerusalem, 1995). The 10-item scale is scored on a 4-point scale $(1=$ not at all true to 4 = exactly true $)$. A typical item is: "When I am confronted with a problem, I can find several solutions.". Cronbach's alpha value of reliability for the whole scale was .92 .

The Hungarian version of the Satisfaction With Life Scale (SWLS; Diener, Emmons, Larsen, \& Griffin, 1985) was used to assess subjective well-being and the respondents' life as a whole. The five items are scored on a 1-7 scale with items such as "The conditions of my life are excellent." A higher summary score indicates greater life satisfaction. Cronbach's alpha coefficient of the scale for this sample was .88.

\section{Ethical Considerations}

Participation was voluntary, and all participants agreed that completion of the questionnaire was construed as consent. Approval to conduct the study was obtained from the Institutional Review Board at (IRB) at the University of Szeged, Doctoral School of Education (ref. no.: 6/2017).

\section{Results \\ Descriptive Statistics and Correlation Matrix}

Social phobia showed strong negative correlation with selfefficacy $(r(392)=-.53 ; p<.001)$ and medium-sized negative correlation with satisfaction with life $(r(392)=-.35 ; p<.001)$, but it was strongly correlated with trait anxiety $(r(392)=.66$; $p<.001)$ and perfectionism $(r(392)=.42 ; p<.001)$ (see Table 1). While satisfaction with life correlated positively with self-efficacy only $(r(392)=.39 ; p<.001)$, there were strong negative correlations with trait anxiety $(r(392)=-.64 ; p<.001)$ and social phobia $(r(392)=-.35 ; p<.001)$, as well as a weaker but still significant negative connection with perfectionism $(r(392)=-.20 ; p<.001)$. There was no correlation between perfectionism and self-efficacy.

\section{Mediation Analysis}

The path analysis was carried out using MPlus 8.0 (Muthén \& Muthén, 1998-2017). The maximum likelihood estimation was used to estimate the models. Bootstrapping with 500 samples was used to estimate the bias-corrected confidence intervals. The originally proposed model (Figure 1) had to be modified in order to avoid the multicollinearity and the negative suppressor effect due to the strong correlations of the predictor variables (see correlation matrix in Table 1). Trait anxiety was therefore removed. In addition, because the main focus was on the mediation analysis, self-efficacy also had to be removed from the model due to its nonsignificant correlation with perfectionism. The final model with standardized estimates is depicted in Figure 2. This model is fully saturated; therefore, the fit indices are not informative.

The mediated effect of perfectionism $\rightarrow$ social phobia $\rightarrow$ satisfaction with life was significant $(-0.14, p<.001,95 \% \mathrm{CI}$ $[-.19,-.09])$ and accounted for almost the total effect $(-0.16$, $p<.002,95 \%$ CI [-.26, -.06]). Arrows represent the assumed causal direction. The unexplained direct effect between perfectionism and satisfaction with life became non-significant and close to zero.

\section{Figure 1}

\section{The Originally Proposed Model}

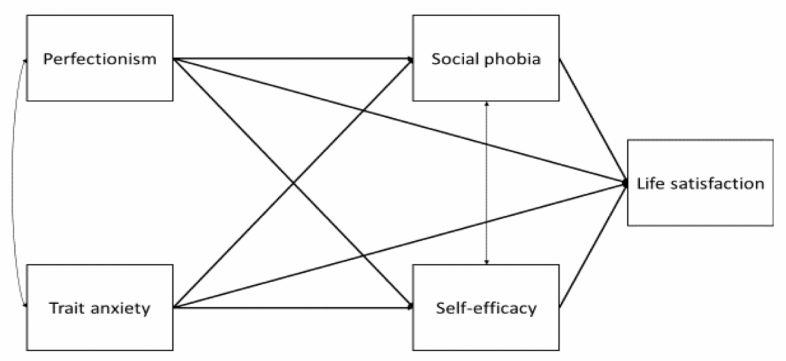

Figure 2

The Final Mediation Model

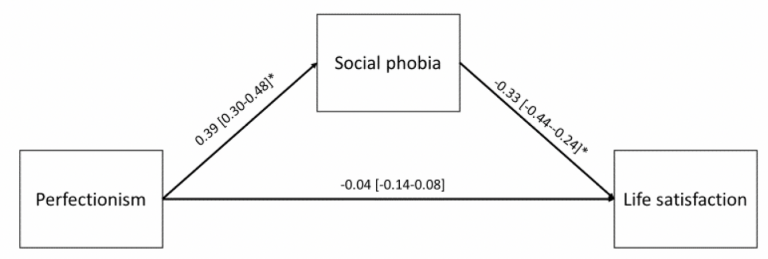

Note: Standardized regression coefficients and bootstrap-corrected confidence intervals for standardized path coefficients [in parentheses] are reported. ${ }^{*} p<.001$.

\section{Discussion}

This study explored the interrelationships between social phobia, trait anxiety, perfectionism and self-efficacy, and whether these variables predicted or contributed to satisfaction with life in a sample of young women aged between 18 and 35 . In addition to bidirectional associations, a path model was also tested. In this sample, the mean score for social phobia was 25.35, higher than the original cut-off score of 19 (Connor et al., 2000), which presented the opportunity to examine perfectionism and satisfaction with life in a population with elevated social phobia. Antony and Barlow (2002) Antony and Barlow (2002) suggested that trait anxiety was a significant factor in the development of social phobia. In the present study, social phobia was positively correlated with trait anxiety, and due to this strong correlation, trait anxiety had to be removed 
The Mediating Role of Social Phobia Between Perfectionism and Low Life Satisfaction Among Young Women

Table 1

Descriptive Statistics and Zero-Ordered Correlation Matrix of the Variables $(N=394)$

\begin{tabular}{lccccc}
\hline Variable (Scale) & $\mathbf{1}$ & $\mathbf{2}$ & $\mathbf{3}$ & $\mathbf{4}$ & $\mathbf{5}$ \\
\hline 1. Social phobia & & & & & \\
2. Satisfaction with life & $-0.35^{* * *}$ & & & & \\
3. Self-efficacy & $-0.53^{* * *}$ & $0.39^{* * *}$ & & & \\
4. Perfectionism & $0.42^{* * *}$ & $-0.20^{* * *}$ & -0.05 & & \\
5. Trait anxiety & $0.66^{* * *}$ & $-0.64^{* * *}$ & $-0.60^{* * *}$ & $0.47^{* * * *}$ & \\
\hline Mean & 25.35 & 23.68 & 30.24 & 85.38 & 46.6 \\
SD & 15.93 & 6.19 & 6.15 & 21.65 & 12.21 \\
Cronbach $\alpha$ & 0.94 & 0.88 & 0.92 & 0.92 & 0.93 \\
\hline$* * * p<001$. & & & & &
\end{tabular}

from the path analysis in order to avoid the negative suppressor effect. Another contributor was maladaptive perfectionism, a personality trait that represents a need for an impeccable, flawless outcome, which might lead to recurrent experiences filled with anxiety (Bieling et al., 2004; Blumenthal et al., 2019; de Bles et al., 2019; Egan et al., 2011). In line with previous findings (Nepon et al., 2011), there was a strong correlation between social phobia and perfectionism. As expected, perfectionism was also positively correlated with trait anxiety and negatively correlated with life satisfaction. These findings are in concordance with previous research (see e.g. Chen et al., 2017; Nepon et al., 2011).

In the final path model, the mediated effect of perfectionism, social phobia and satisfaction with life was significant, while the direct effect between perfectionism and satisfaction with life was nonsignificant. This finding suggests that perfectionism can indirectly affect life satisfaction through its enhanced effect on social phobia. Concerns about mistakes in social settings as well as doubts about actions may contribute to the development of social phobia and experience of shame, which is present in both social phobia and perfectionism (Egan et al., 2011). Individuals with social fears and perfectionistic tendencies are motivated towards making a desired impression, but discrepancy with the inability of doing so can trigger feelings like anxiety, fear and shame. Furthermore, perfectionism does not necessarily contribute to lower life satisfaction, thus, necessitating the distinction between maladaptive and adaptive perfectionism (Bieling et al., 2004). However, when maladaptive perfectionism evolve into social phobia, individuals might become preoccupied with personal flaws. The fear of making a mistake causes excess worry, rumination and avoidance of social situations, which in turn can generate more psychological distress and less satisfaction with life.

The correlation analysis showed that women who had higher self-efficacy reported greater satisfaction with life. This finding was similar to previous research (see e.g. Çakar, 2012; van Zyl \& Dhurup, 2018). In addition, trait anxiety and social phobia were negatively correlated with self-efficacy. This indicates that social functioning is impaired if there is a lack of self-efficacy (Tahmassian \& Moghadam, 2011). On the other hand, self-efficacy was not correlated with perfectionism, and was therefore removed from the path analyses. While these findings support previous findings that higher self-efficacy underpins psychological well-being and life satisfaction (Burger \& Samuel, 2017), it may not play a mediating role in the interrelationships among perfectionism, social phobia and satisfaction with life.

These findings have some limitations. Since we applied a cross-sectional study design, a cause-and-effect relationship cannot be inferred. The data were collected from a specific age group of women, using an online questionnaire consisting of mainly screening tools that do not provide clinical diagnoses.

Overall, these results support the role of social phobia in young women's lower satisfaction with life. In addition, perfectionism - indirectly, through developing social phobia may also contribute to lower levels of life satisfaction, while self-efficacy does not mediate these interrelationships. Indeed, the most important finding suggests that perfectionism indirectly affects satisfaction with life through its contribution to the experience of social phobia. Further research should examine more resilience factors that may neutralize the negative effects of perfectionism and social phobia on life satisfaction. For example, previous studies suggest that social connectedness (Gnilka, Broda, \& The Spit for Science Working Group 2018, 2019), obtainable self-expectations (Sherry, Mackinnon, Macneil, \& Fitzpatrick, 2013) and the ability to regulate one's emotions (Aldea \& Rice, 2006) can increase personal resilience and reduce negative psychological outcomes. It would be interesting to examine their mediating roles in perfectionism and life satisfaction.

\section{Summary and Conclusion}

The results of the present study highlight the importance of identifying maladaptive perfectionistic tendencies when screening for social anxiety disorders. In this study, women scored higher on the social phobia scale than the normative sample, which indicates that intense anxiety and unrealistic expectations may lead to a lower level of life satisfaction in 
general. Since this study focused particularly on the relationship between social phobia and perfectionism, these findings suggest some practical implications. During psychotherapy, both social phobia/anxiety and perfectionism should be considered as personality factors that greatly reduce quality of life. Seeking therapy may improve social interaction, emotional state and satisfaction with life. Maladaptive perfectionism may be reduced through appropriate parenting and pedagogical practice that avoids imposing unrealistic expectations on the child, and the use of harsh criticism when these standards are not met. Finally, these findings may contribute to a better understanding of young women's social phobia, the role it has in life satisfaction and other correlates.

\section{Funding}

This research received no external funding.

\section{Conflict of Interest}

The authors declare that they have no competing interests.

\section{References}

Aldea, M. A., \& Rice, K. G. (2006). The role of emotional dysregulation in perfectionism and psychological distress. Journal of Counseling Psychology, 53(4), 498-510.

Antony, M. M., \& Barlow, D. H. (2002). Specific phobias. In D. H. Barlow (Ed.), Anxiety and its disorders - the nature and treatment of anxiety and panic (p. 380-417). London: The Guilford Press.

Auerbach, R. P., Mortier, P., Bruffaerts, R., Alonso, J., Benjet, C., Cuijpers, P., ... Kessler, R. C. (2018). WHO world mental health surveys international college student project: Prevalence and distribution of mental disorders. Journal of Abnormal Psychology, 127(7), 623-638.

Bandelow, B., \& Michaelis, S. (2015). Epidemiology of anxiety disorders in the 21st century. Dialogues in Clinical Neuroscience, 17(3), 327-335.

Bandura, A. (1977). Self-efficacy: Toward a unifying theory of behavioral change. Psychological Review, 84(2), 191215.

Bautista, C. L., \& Hope, D. A. (2015). Fear of negative evaluation, social anxiety and response to positive and negative online social cues. Cognitive Therapy and Research, 39(5), 658-668.

Baxter, A., Vos, T., Scott, K., Ferrari, A., \& Whiteford, H. (2014). The global burden of anxiety disorders in 2010. Psychological Medicine, 44(11), 2363-2374.

Bieling, P. J., Israeli, A. L., \& Antony, M. M. (2004). Is perfectionism good, bad, or both? examining models of the perfectionism construct. Personality and Individual Differences, 36(6), 1373-1385.

Blumenthal, H., Taylor, D. J., Cloutier, R. M., Baxley, C., \& Lasslett, H. (2019). The links between social anxiety disorder, insomnia symptoms, and alcohol use disorders: findings from a large sample of adolescents in the united states. Behavior Therapy, 50(1), 50-59.
Burger, K., \& Samuel, R. (2017). The role of perceived stress and self-efficacy in young people's life satisfaction: A longitudinal study. Journal of Youth and Adolescence, 46(1), 78-90.

Çakar, F. S. (2012). The relationship between the self-efficacy and life satisfaction of young adults. International Education Studies, 5(6), 123-130.

Chen, L., Zhong, M., Cao, X., Jin, X., Wang, Y., Ling, Y., ... Yi, J. (2017). Stress and self-esteem mediate the relationships between different categories of perfectionism and life satisfaction. Applied Research in Quality of Life, 12(3), 593-605.

Connor, K. M., Davidson, J. R., Churchill, L. E., Sherwood, A., Weisler, R. H., \& Foa, E. (2000). Psychometric properties of the social phobia inventory (SPIN): New self-rating scale. The British Journal of Psychiatry, 176(4), 379-386.

de Bles, N. J., Ottenheim, N. R., van Hemert, A. M., Pütz, L. E., van der Does, A. W., Penninx, B. W., \& Giltay, E. J. (2019). Trait anger and anger attacks in relation to depressive and anxiety disorders. Journal of Affective Disorders, 259, 259-265.

Diener, E., Emmons, R., Larsen, R., \& Griffin, S. (1985). The life satisfaction scale. Journal of Personality Assessment, 49(1), 71-75.

Dryman, M. T., Gardner, S., Weeks, J. W., \& Heimberg, R. G. (2016). Social anxiety disorder and quality of life: How fears of negative and positive evaluation relate to specific domains of life satisfaction. Journal of Anxiety Disorders, 38, 1-8.

Egan, S. J., Wade, T. D., \& Shafran, R. (2011). Perfectionism as a transdiagnostic process: A clinical review. Clinical Psychology Review, 31(2), 203-212.

Frost, R. O., Marten, P., Lahart, C., \& Rosenblate, R. (1990). The dimensions of perfectionism. Cognitive Therapy and Research, 14(5), 449-468.

Gnilka, P. B., Broda, M. D., \& The Spit for Science Working Group 2018. (2019). Multidimensional perfectionism, depression, and anxiety: Tests of a social support mediation model. Personality and Individual Differences, 139, 295-300.

Hart, B. A., Gilner, F. H., Handal, P. J., \& Gfeller, J. D. (1998). The relationship between perfectionism and self-efficacy. Personality and Individual Differences, 24(1), 109-113.

Heeren, A., \& McNally, R. J. (2018). Correction to: Social anxiety disorder as a densely interconnected network of fear and avoidance for social situations. Cognitive Therapy and Research, 42(6), 878-879.

Jefferson, J. W. (2001). Social anxiety disorder: More than just a little shyness. Primary Care Companion to the Journal of Clinical Psychiatry, 3(1), 4-9.

Merikangas, K. R., Avenevoli, S., Acharyya, S., Zhang, H., \& Angst, J. (2002). The spectrum of social phobia in the Zurich cohort study of young adults. Biological Psychiatry, 51(1), 81-91. 
Morina, N., Bryant, R. A., Doolan, E. L., Martin-Sölch, C., Plichta, M. M., Pfaltz, M. C., ... Nickerson, A. (2018). The impact of enhancing perceived self-efficacy in torture survivors. Depression and Anxiety, 35(1), 58-64.

Muthén, L. K., \& Muthén, B. O. (1998-2017). Mplus user's guide. (8th ed.) Los Angeles, CA: Muthén \& Muthén.

Nepon, T., Flett, G. L., Hewitt, P. L., \& Molnar, D. S. (2011). Perfectionism, negative social feedback, and interpersonal rumination in depression and social anxiety. Canadian Journal of Behavioural Science, 43(4), 297-308.

Schwarzer, R., \& Jerusalem, M. (1995). Generalized selfefficacy scale. In J. Weinman, S. Wright, \& M. Johnston (Eds.), Measures in health psychology: A user's portfolio causal and control beliefs (p. 35-37). NFERNELSON.

Sherry, S. B., Mackinnon, S. P., Macneil, M. A., \& Fitzpatrick, S. (2013). Discrepancies confer vulnerability to depressive symptoms: A three-wave longitudinal study. Journal of Counseling Psychology, 60(1), 112-126.

Spielberger, C. D., Gorsuch, R. L., \& Lushene, R. E. (1970). Manual for the state-trait anxiety inventory. CA: Consulting Psychologists Press.

Tahmassian, K., \& Moghadam, N. J. (2011). Relationship between self-efficacy and symptoms of anxiety, depression, worry and social avoidance in a normal sample of students. Iranian Journal of Psychiatry and Behavioral Sciences, 5(2), 91-98.

van Zyl, Y., \& Dhurup, M. (2018). Self-efficacy and its relationship with satisfaction with life and happiness among university students. Journal of Psychology in Africa, 28(5), 389-393. 